Bond University

Research Repository

\title{
Emotions in organizations
}

Fisher, Cynthia D

Published in:

Oxford Research Encyclopedia of Business and Management

DOI:

10.1093/acrefore/9780190224851.013.160

Licence:

Other

Link to output in Bond University research repository.

Recommended citation(APA):

Fisher, C. D. (2019). Emotions in organizations. In R. J. Aldag (Ed.), Oxford Research Encyclopedia of Business and Management Oxford University Press. https://doi.org/10.1093/acrefore/9780190224851.013.160

\section{General rights}

Copyright and moral rights for the publications made accessible in the public portal are retained by the authors and/or other copyright owners and it is a condition of accessing publications that users recognise and abide by the legal requirements associated with these rights.

For more information, or if you believe that this document breaches copyright, please contact the Bond University research repository coordinator. 


\section{Title: Emotions at Work}

\section{Author: Cynthia D. Fisher}

Written for The Oxford Research Encyclopedia of Business and Management, submitted September 2017

Keywords: Emotions at work; emotions in organizations, affect at work, affect in organizations, affective events theory, positive emotions at work

\section{Summary}

There has been an "affective revolution" in organizational behavior since the mid-1990s, focusing initially on moods and affective dispositions. The past decade has seen a further shift toward investigating the complex roles played by discrete emotions in the workplace. Discrete emotions such as fear, anger, boredom, love, gratitude, and pride each have their own appraisal antecedents, subjective experiences, and action tendencies which prepare people respond to their current situation. Emotions have intrapersonal effects on the person experiencing them in terms of attention, motivation, creativity, information processing and judgement, and well-being. Some emotions also have characteristic voice tones or facial expressions (e.g. disgust is universally shown by raising the upper lip and wrinkling the nose bridge) that serve the interpersonal function of communicating one's state to interaction partners. For this reason, emotions are integral to social processes in organizations such as leadership, teamwork, negotiation, and customer service. The effects of emotions on behavior can be complex and context-dependent rather than straightforwardly mechanistic. Individuals may regulate the emotions they experience, the extent to which they display what they feel, and the actions they choose in response to how they feel. 
Research has tended to focus on negative emotions (such as anger or anxiety) and their potential negative effects (e.g. aggression or avoidance), whereas in fact negative emotions can have positive consequences at times. Discrete positive emotions have been relatively ignored in organizational research, though feeling and expressing positive emotions often (but not always) have positive consequences. There is considerable scope for investigating the ways that specific discrete emotions are experience, regulated, expressed, and acted upon in organizational life. There may also be a case for intentional efforts by organizations and employees to increase the occurrence of positive emotions at work in a variety of ways.

\section{(End of summary. Main document follows.)}

For many years emotions in the workplace were ignored altogether, or regarded as irrational and hence having no place in organizations which were thought to be bastions of rationality, or considered merely a source of annoying unreliability in the reporting of more stable work attitudes and perceptions. This has been changing over the past four decades. In 1983, Hochschild’s book The Managed Heart: Commercialization of Human Feeling introduced the concept of emotional labor, in which employees are required to display prescribed emotions to customers whether or not they genuinely feel those emotions. Subsequent papers by Pekrun and Frese (1992) on emotions in work and achievement, Ashforth and Humphey (1995), and especially Weiss and Cropanzano’s (1996) chapter introducing Affective Events Theory, kickstarted research on affect at work. By 2003, Barsade, Brief, and Spataro were writing about an “affective revolution in organizational behavior,” and the pace of research has accelerated substantially since then (e.g. Elfenbein, 2007). 
Much of the early work on affect in organizations focused on mood, defined by the dimensions of hedonic tone (pleasant to unpleasant) and arousal (high to low). More recently, research has extended to short-lived discrete emotional experiences such as anger, boredom, and gratitude. Emotions have specific targets (one is angry about something, or feels love for a particular person) and most emotions have action tendencies that orient individuals to operate on the target of the emotion (e.g., approach in the case of love). The next section draws on social psychology to briefly describe what emotions are, the functions they serve, and in general how they influence behavior. I will then turn to a more specific examination of the role and impacts of emotions in organizations, review research related to a sample of discrete emotions relevant to the workplace, describe how individuals regulate and/or express emotions at work, and consider implications for future research including intentional efforts to increase the experience of positive emotions while working.

\section{What are Emotions and How Do They Work?}

An emotion is an organized system of feelings, physiological responses, bodily expressions, and action tendencies that flow from an almost instantaneous appraisal of a current situation's relevance to the individual (Scherer, 2005). The primary appraisal includes a quick assessment of whether an event is relevant to the perceiver and if so, whether it is good or bad for their goals. A more detailed secondary appraisal of the specific cause, degree of threat or benefit, certainty, coping potential, and so on results in the experience of a particular discrete emotion (Lazarus, 1991; Smith \& Ellsworth, 1985). For instance, fear is felt in connection with appraisals of very high uncertainty and high external control and unpleasantness. Emotions provide a read-out of one's current state of affairs, such that positive emotions indicate that things are going well and negative emotions indicate a problematic situation. The functional 
approach to emotions holds that emotions evolved to serve adaptive purposes by interrupting ongoing activities, redirecting attention, and leading to a reprioritization of goals so that a current problem can be addressed. Emotions also prepare and motivate a coordinated response to that problem (Keltner \& Gross, 1999), with different discrete emotions guiding responses to different kinds of problems (Lench, Flores, \& Bench, 2011). For instance, fear prepares one mentally and physiologically for escape, and anger prepares one to engage with the source of goal blockage. Socially functional emotions, such as embarrassment, shame, disgust, anger, gratitude, and love, also communicate internal states to others and guide interpersonal interactions (e.g. Van Kleef, 2014).

Valence. While emotions contain much more information than valence alone, positive or negative valence is the most fundamental differentiator between different emotions (e.g. Shaver, Schwartz, Kirson, \& O’Connor, 1987). Negative emotions have historically attracted considerably more research attention than positive ones. Negative states such as depression and stress and emotions such as anger and fear are highly relevant to individual mental health as well as to society and thus have been extensively studied by clinical and social psychologists. Lexical analyses show that there are more words in the English language for negative emotions than for positive emotions (e.g. Averill, 1980). In lists of the "basic emotions” considered universal, negative emotions substantially outnumber positive ones (Ortony \& Turner, 1990). A case in point is Izard's list (1977), with joy and interest being positive and all the rest being negative (fear, anger, disgust, contempt, distress, guilt, shame). In an extensive cluster analysis of natural categories and prototypes of emotion concepts, Shaver et al. (1987) confirmed that there are more distinct ways to feel bad than to feel good. While experiencing positive emotions is more common than negative emotions and most people feel at least a little positive most of the time 
(the “positivity offset,” Diener \& Diener, 1996), we know that "bad is stronger than good” in the case of emotions and their effects (Baumeister, Bratslavsky, Finkenauer, \& Vohs, 2001). Because they are less common, negative emotions are more distinctive and memorable than positive emotions. They also tend to be longer lasting, more intense, and generally more problematic. This may be because negative emotions and the situations that trigger them are less expected, often imply a violation of norms or values, threaten important goals, and are more likely to require a specific response (e.g. Thomas \& Diener 1990).

Only in the last two decades have psychologists turned substantial attention to positive emotions, flourishing, and vibrant well-being rather than the reduction of negative emotions, stress, illness, and disease. The various positive emotions have more similar appraisal structures and less distinctive physiological signatures than the negative emotions, though some are empirically discriminable (De Rivera, Possell, Verette, \& Weiner, 1989; Hu \& Kaplan, 2015). Positive emotions signal that things are going well and consequently have less clear or urgent action tendencies, but they do serve a purpose. In her Broaden and Build model, Fredrickson (1998) suggests that the positive emotions of joy, interest, contentment, and love serve the adaptive function of broadening an individual's momentary thought-action repertoire. This may result in creativity, exploration, and general approach tendencies that build intellectual and social resources, thereby enhancing resilience for the future. Further, the experience of positive emotions may fuel upward spirals of well-being and serve to "undo" the effects of stress and negative emotions. I will contend that positive emotions deserve more attention in organizational behavior research, and that organizations and individuals may benefit from consciously cultivating the more frequent experience of positive emotions. 
Emotions and behavior. While emotions of both valences have action tendencies, they do not directly cause a specific behavior in a deterministic or hardwired process. Strong emotions may sometimes provoke impulsive action, but often action tendencies are moderated and responses chosen more carefully. In fact, the same emotion may have quite different behavioral effects depending on individual and situational differences (e.g. Tai, Narayanan, \& McAllister, 2012). Baumeister, Vohs, DeWall, and Zhang (2007) point out that emotions do not

automatically cause behavior, as in “fear makes you flee.” Rather, emotions trigger a more contextually sensitive process resulting in action. They suggest that "behavior pursues emotion...people act on the basis of anticipated emotions rather than current ones” (Baumeister et al., 2007, p. 195). For instance, Brown and McConnell (2011) showed that anticipated emotions about how one would feel if they didn’t reach a goal predicted goal-directed action. Van der Schalk, Kuppens, Bruder, and Manstead (2015) showed that anticipated regret reduced unfair treatment of others. In a work context, Grant and Wrzesniewski (2010) demonstrated that anticipated guilt and gratitude mediated the relationship between core self-evaluations and performance for employees high on other orientation. It may be most appropriate to think of emotions as the fuel, affect regulation as the brakes, and cognition, including thoughts about anticipated emotions, as the steering wheel guiding action tendencies (except when rocket fuel has been ignited).

\section{Why Study Emotions in Organizations?}

Emotions are pervasive in work organizations. First, organizations are populated by people, and people can't help having emotions about things which matter to them. Organizations are achievement settings in which goal pursuit and professional identity often matter deeply, so emotions follow (Fisher, 2008; Pekrun \& Frese, 1992). Organizations are also social settings in 
which individuals work with peers, bosses, subordinates, and customers. These relationships can go well or poorly and matter to people, so again, emotions are experienced. Finally, as pointed out by Ashkanasy and Dorris (2017), while emotions occur at the individual level and fluctuate within person over time, they also have relevance for higher levels of analysis in organizations. Both parties’ emotions are central to dyadic processes in leadership, negotiation, conflict, and customer service. Individuals' emotions may aggregate to create group level phenomena such as group affective tone (Barsade \& Knight, 2015; Collins, Lawrence, Troth, \& Jordan, 2013; George \& King, 2007; Menges \& Kilduff, 2015). At the organizational level, there may be a characteristic affective climate that sets norms for the experience and expression of emotions in that organization (Parke \& Seo, 2017). Although emotions can be studied at multiple levels, the remainder of this chapter will focus on the person level where emotions are generated and experienced in real time. In this regard, it seems reasonable to begin by presenting Weiss and Cropanzano’s (1996) Affective Events Theory, which was instrumental in stimulating the recent outpouring of research on mood and emotions in the workplace.

\section{Affective Events Theory}

Weiss and Cropanzano’s (1996) Affective Events Theory (AET) drew attention to the real time nature and causes of emotions (and moods) at work. They shifted the focus from stable work environment features such as job design to the more immediate level of specific affective events such as an accomplishment, an incident of feedback, an interaction with another person, a goal blockage of some sort, etc. (e.g. Basch \& Fisher, 2000; Herzberg, Mausner, \& Snyderman, 1959; Ohly \& Schmitt, 2015). Work environment features may predispose the more or less frequent occurrence of certain affective events, but it is the event itself that triggers the appraisal process and the real-time experience of an emotion. The emotion may sometimes lead to fairly 
spontaneous affect driven behavior as the individual reacts to the immediate situation and the way they are feeling at the moment. Examples of such spontaneous acts may include helping or counterproductive work behavior, among others. Over time, emotions experienced in connection with a succession of work events are hypothesized to cumulate to influence more stable attitudes such as job satisfaction and organizational commitment, and these in turn predict judgement driven behavior such as turnover. There is some support for many of the ideas put forward in Affective Events Theory (e.g., Fisher 2002; Wegge, Dick, Fisher, West, \& Dawson, 2006; Weiss \& Beal, 2005).

An elaboration of AET was proposed by Veiga, Baldridge, and Markoczy (2014). They were speculating specifically about how a series of affective events involving the emotion of envy might cumulate to more intense feelings of envy over time, but their ideas should generalize to any emotion. They suggest that if there is a history of prior events in the workplace, each of which has evoked the same emotion, a schema is created and is increasingly accessible. This means that a future event of a similar nature is likely to be quickly appraised and give rise to the same emotion but with greater intensity and consequently a stronger response than the current affective event alone might seem to warrant.

\section{Effects of Emotions in Organizations}

Emotions clearly have hedonic relevance to the person experiencing them, both immediately and cumulatively in terms of health and well-being (Lyubomirsky, King, \& Diener, 2005). They also have impacts on individual behavior and interpersonal relationships. It is often assumed that positive and negative emotions have symmetrical consequences, with positively valent emotions producing positive consequences and negatively valent emotions producing negative consequences. While this may often be true, there are many examples of asymmetrical 
effects (Lindebaum \& Jordan, 2014; Lindebaum, Jordan, \& Morris, 2016; Van Knippenberg \& Van Kleef, 2016). For instance, Lebel (2017) discusses when fear and anger may stimulate proactivity resulting in functional outcomes for individuals and organizations. Ilies, Peng, Savani, and Dimotakis (2013) demonstrate that guilt induced by feedback about counterproductive work behavior enhances subsequent organizational citizenship behavior. The effects of emotions and their expression are wide-ranging, complex, and contingent. The following sections briefly describe the roles emotions may play in a variety of workplace domains.

Emotions and decision making. There is a considerable literature on affective biases and heuristics in decision making (e.g. Slovic, Finucane, Peters, \& MacGregor, 2007). More recently attention has turned to the way that specific emotions might influence decision making beyond simple valence or arousal effects. Lerner, Li, Valdesolo, and Kassam (2015) review the nascent but growing literature on emotions in decision making and judgment and conclude that, “emotions constitute potent, pervasive, predictable, sometimes harmful and sometimes beneficial drivers of decision making...via changes in (a) content of thought, (b) depth of thought, and (c) content of implicit goals...” (p. 816). The valence of current emotions, whether or not they are relevant to and flowing from the decision task at hand, may be taken as information about the advisability or otherwise of the decision. The appraisal dimensions most salient to a recently experienced emotion, e.g., other blame in the case of anger or uncertainty in the case of fear, as well as the action tendencies for that emotion, e.g. attack in the case of anger, escape/avoid in the case of fear, may color perceptions of an unrelated decision problem. In addition, aspects of the emotion can influence whether automatic/heuristic processing or systematic processing is used in making the decision. At this point in time, we know relatively little about how real-time 
emotions might influence or bias decision making in organizational settings, but it seems likely that they do.

Emotions and sensemaking. Sensemaking is the process by which individuals create meaning in the uncertain or ambiguous situations often found in organizations. Maitlis, Vogus, and Lawrence (2013) suggest that emotions might play important roles at three stages in the sensemaking process. First, emotions may help initiate sensemaking. Sensemaking occurs when there is a surprising or unexpected event or result that does not fit the current mental model. The emotions that arise from this discrepancy, particularly if they are negative and relatively intense, are likely to both attract attention to the need for sensemaking and provide the energy to engage in this demanding cognitive activity. Second, emotions experienced during sensemaking may influence results by the kind of cognitive processing they trigger. Positive emotions often result in more flexible and generative thinking, whereas negative emotions stimulate careful and critical thinking. Specific emotions may also condition whether sense making is conducted socially or alone. Emotions like shame are especially likely to result in solitary sensemaking. Third, emotions may help inform sensemakers of when their new model makes enough sense - if it resonates with the emotions they are current feeling and appears to provide a useful guide to applying that emotion's action tendency, sensemaking may cease.

Emotions and leadership. Leadership represents an interpersonal relationship between the leader and individual followers or between the leader and a group. The relationship often has high importance for all parties, so it is not surprising that it is emotionally charged and that felt and expressed emotions are critical to the relationship on both sides. The importance of positive emotions in charismatic, transformational, and authentic leadership has long been appreciated, and the past decade has seen an explosion of research on emotions in leadership and followership 
(see Van Knippenberg and Van Kleef (2016) and Humphrey, Burch, \& Adams (2016) for recent reviews). Sample topics include how the expression of specific emotions by leaders contributes to the perception of leadership (e.g. Eberly \& Fong, 2013), how leaders can intentionally induce or regulate emotional experiences among followers (e.g. Kaplan, Cortina, Ruark, LaPort, \& Nicolaides, 2014; Thiel, Connelly, \& Griffith, 2012), how leader emotional displays affect subordinate motivation, engagement, and performance (e.g. Koning \& Van Kleef, 2015; Visser, Van Knippenberg, Van Kleef, \& Wisse, 2013), how emotions play out in the formation of leader-member exchange relationships (e.g. Cropanzano, Dasborough, \& Weiss, 2017), how emotions are involved in poor leader-member relationships in the form of spirals of abusive supervision (e.g. Oh \& Farh, 2017), and the complex contingencies governing effective leader emotional expression (e.g. Jordan \& Lindebaum, 2015; Rothman \& Melwani, 2017).

Emotions and negotiation. Research on the role of emotions in negotiation is increasing (e.g., Martinovski, 2015; Overbeck, Neale, \& Govan, 2010; Sinaceur, Van Kleef, Neale, Adam, \& Haag, 2011). Issues involve the emotions felt by the parties, as well as their expressive displays (be they authentic or strategic), and the impact on negotiating outcomes. Emotions impact negotiators' cognitions and inferences about the other party’s trustworthiness, motives and willingness to make concessions. Anger and happiness are frequently studied (e.g. Allred, Mallozzi, Matsui, \& Raia, 1997; Van Kleef \& Côté, 2007); other emotions beginning to attract research in a negotiation context include disappointment, regret, fear, anxiety, and guilt. Positive emotions have been relatively neglected in the negotiation context, though the evidence suggests that they facilitate agreement, trust, and a longer-term relationship between the parties (see Olekalns and Druckman, 2014, for a review). 
Emotional labor. Emotional labor occurs when employees modify or suppress the emotions they are feeling in order to display the emotions mandated by the organization, often in a customer service setting. This concept has attracted a great deal of research since 1990, and a review of the antecedents, processes, and outcomes of emotional labor is provided by Grandey and Gabriel (2015). Historically, two responses to organizational display rules have been studied in the emotional labor literature. One is deep acting, which occurs when employees change how they feel so that they can deliver the desired (usually positive) demeanour to customers, e.g., perhaps thinking of a happy event or trying to take the customer's perspective to create positive emotions and thus facilitate the delivery of friendly and helpful service. The second is surface acting, in which employees do not change their underlying (usually negative) emotions but attempt to suppress their display and fake the (usually positive) demeanour expected by the employer. Employees who surface act may experience emotional dissonance.

Meta-analyses suggest that surface acting is generally detrimental to employee well-being (Hülsheger \& Schewe, 2011; Kammeyer-Mueller et al., 2013). This would be expected from the more general literature on emotion regulation, which suggests that suppression of negative emotions is often harmful (Chervonsky \& Hunt, 2017). Evidence for the organizational outcomes of emotional labor for service provider performance and customer reactions are somewhat weaker. Expressing positive (or supressing negative) emotions may improve customer service perceptions by emotional contagion to the customer as well as by providing cues about the quality and motivations of the organization or the service provider. Genuine or deep acted (versus surfaced acted) positive emotional expressions seem to amplify these desirable effects (Grandey and Gabriel, 2015). 
The single-minded focus on deep versus surface acting as stressors in emotional labor research has recently begun to broaden. First, because the vast majority of research on emotional labor has been in situations with positive emotion display rules, employees who report engaging in surface acting are those who initially felt and continue to feel negative emotions. The apparent adverse effects of surface acting on well-being may flow at least as much from feeling negative emotions as from acting to suppress the display of those emotions (Semmer, Messerli, \& Tschan, 2016). Second, Grandey and Melloy (2017) point out that there is an alternative to acting - the authentic expression of emotion by employees who genuinely feel positive and display these positive emotions to customers without the use of any intervening emotion regulation strategy. Third, Humphrey, Ashforth, and Diefendorff (2015) suggest a bright side to emotional labor. They marshal evidence that it is healthy and satisfying for employees to display positive emotions, whether deep acted or authentic. These advances suggest the need for more research on how to help employees feel authentic positive emotions so there is less need to act.

\section{Discrete Emotions in Organizations}

We have seen that emotions are implicated in a wide range of organizational processes. I will now turn to a discussion of some specific emotions that may be relevant in organizations. While anger and boredom in the workplace have been fairly well studied, a number of other discrete emotions have attracted less attention but have the potential to generate useful insights relevant to behavior, performance, and well-being. Positive emotions have been particularly overlooked. Hu and Kaplan (2015) note the generally positive relationships between positive affect and desirable outcomes both in life and at work, but suggest that it is time to go beyond positive affect to discrete positive emotions which have unique antecedents and outcomes. They 
discuss and theorize about three such emotions likely to be common and impactful at work: pride, interest, and gratitude. These and others will be discussed below.

Pride. "Pride is a self-focused positive emotion triggered by appraisals of the self's success, status, and competence” (Horberg, Kraus, \& Keltner, 2013, p. 24). Pride may be based on a private self-appraisal of performance or competence, or on recognition or public praise from others. There is a considerable literature on pride in social psychology, but relatively little research on pride in the organizational behavior literature. This is surprising because organizations are settings in which achievement is often evaluated and rewarded, and job performance/competence is integral to many employees' self-concepts. In fact, pride was the second most frequently experienced workplace emotion (behind joy) in a survey of sales people (Verbeke, Belschak, \& Bagozzi, 2004). As discussed below, pride has intrapersonal effects on motivation and persistence as well as interpersonal effects on those observing a display of pride.

There appear to be two distinct types of pride, with different appraisal structures and effects (Tracy \& Robins, 2007). Hubristic pride is pride in stable attributes of the global self ("I am a perfect person”) and is correlated with narcissism, poor self-esteem, impulsiveness, aggression, and poor self-control (e.g. Carver, Sinclair, \& Johnson, 2010; Tracy \& Robins, 2007). It is generally dysfunctional and tends to alienate others, and is described in theology as the original and most damaging of the seven deadly sins. In contrast, authentic pride is based on specific personal achievements which are attributed to internal, unstable, and controllable causes such as effort. Authentic pride is positively associated with self-esteem, self-control, intrinsic motivation, and conscientiousness, and seems much more likely to have positive consequences (Carver et al., 2010; Tracy \& Robins, 2007). Recently, Buechner, Pekrun, and Lichtenfeld (2016) have broken down authentic pride into self-based pride, felt when one achieves a higher 
standard than one did in the past, and social-comparison-based pride, felt when one performs better than specific others. It seems likely that the type of feedback (absolute vs. comparative) which would provoke each type of pride, and post-pride feelings and actions, might vary between these types. For instance, Buechner et al. suggest that social-comparison-based pride might result in feelings of contempt for those bested, whereas self-based pride should further enhance mastery motivation.

Pride provides a read-out of the current state of goal progress or goal success, as well as motivating future adaptive behavior. Williams and DeSteno (2008) hypothesized that pride could enhance persistence on tasks despite their short-term hedonic costs in the form of effort or boredom. In two studies, they demonstrated that pride induced by positive feedback delivered with praise enhanced persistence on a second task of a similar nature, did so over and above the effects of self-efficacy, and did so more than a positive affect induction without the pride treatment. Weidman, Tracy, and Elliot (2016) found that authentic pride was negatively related to plans to change one's approach to training or study in two longitudinal achievement contexts. That is, high pride led to continued use of past successful strategies, while low pride triggered changes in approach that resulted in greater subsequent performance among those who initially performed more poorly. In a vignette study, Verbeke et al. (2004) found that sales people said that feeling pride would increase their effort, self-efficacy, and use of adaptive selling strategies.

Pride also serves social purposes. The physical display of pride is easily recognised by observers, expressed as an upright and expanded posture with the head tilted slightly back, a low intensity smile, and hands on hips or up in the air. These physical displays convey to others the higher relative status of the displayer and may indicate “who’s the boss” (Shariff \& Tracy, 2009), thus helping to establish and clarify social hierarchies. Pride body language also allows 
observers to infer the displayer's likely appraisals and thereby predict other values and preferences of the individual showing pride. In particular, Horbert, Kraus, and Keltner (2013) showed that brief exposure to an individual displaying pride caused observers to infer that the individual was more self-interested and therefore that the individual more strongly supported a meritocratic rather than an egalitarian system of reward distribution. While this study did not focus on the employment context, clearly beliefs about reward systems and their fairness are very important to employees.

Individuals seem to understand that excessive displays of pride may alienate others or create envy, and therefore they regulate its display (Verbeke et al., 2004). In an article entitled, "Don't Grin When You Win: The Social Costs of Positive Emotion Expression in Performance Situations,” Kalokerinos, Greenaway, Pedder, and Margetts (2014) found that when pride was based on winning against others, supressing overt displays of pride and joy was associated with improved social outcomes (ratings of likability and desire for friendship) among observers.

Organizations may attempt to build employee pride by individual recognition as well as collective celebrations. Pride is likely to be facilitated by competitive and individualistic reward practices, the idealized influence and inspirational motivation dimensions of transformational leadership, and performance-approach and mastery goals. While authentic pride may have desirable outcomes for future motivation and achievement, hubristic pride may reduce prosocial behavior and eventually degrade working relationships, as may excessive public displays of pride.

Interest. Interest is sometimes listed as one of the basic emotions, and has even been described as the most frequently experienced emotion (Silvia, 2006). It is one of the four emotions at the heart of Fredrickson's (1998) Broaden-and-Build theory. Interest has a critical 
function, being implicated in goal choice and self-regulation during goal pursuit (e.g. Sansone, Weir, Harpster, \& Morgan, 1992). Interest also motivates the development of competence, and educational psychologists have extensively studied the critical role of interest in the learning process (Renninger \& Hidi, 2016). In the workplace, interest has been implicit in research on intrinsic motivation and flow states as well as job redesign. On the whole, however, interest has not attracted the amount of research it deserves given its likely role in motivation, engagement, competency development, and personal well-being at work. Interest may be facilitated by job redesign, the intellectual stimulation dimension of transformational leadership, mastery goals, and person-job fit. Interest should facilitate learning and creativity, and over the long term the frequent experience of interest at work should increase satisfaction with the work itself and (via creativity) job success.

Gratitude. Gratitude occurs when one appreciates help received from another. It is rarely studied in the workplace but is beginning to attract some attention. For instance, Fehr, Fulmer, Awtrey, and Miller (2017) have proposed a three-level model of gratitude in organizations. They describe episodic gratitude as occurring when a focal person appreciates an incident of help, support, or other benefit voluntarily provided by another party for reasons perceived to be benevolent. At a higher level, persistent gratitude is the stable tendency of a person to experience gratitude and is learned from multiple instances of episodic gratitude. Finally, at the highest level, collective gratitude occurs at the organizational level when feeling and expressing gratitude become part of a shared culture.

Outside of the work context, Davis et al. (2016) and Dickens (2017) report meta-analyses showing that interventions to increase the experience and expression of gratitude can have positive effects on happiness, life satisfaction, and depression. Also in a non-work context, 
being the recipient of a relationship partner's gratitude is associated with the relationship growing stronger over time (Algoe, Fredrickson, \& Gable, 2013). In the workplace, Cheng, Tsui, and Lam (2015) found that keeping a twice weekly work-related gratitude journal reduced stress and depressive symptoms in health care providers compared to no journal or a journal of hassles. Spence, Brown, Keeping, and Lian (2014) assessed naturally occurring daily variations in felt gratitude at work and found that they predicted daily citizenship behavior. Being the recipient of gratitude also seems to be beneficial. Grant and Gino (2010) explored the effect of receiving gratitude from the beneficiaries of one's work or one’s supervisor, and documented a motivational impact on fund-raisers. It seems likely that gratitude experiences at work would encourage social bonds and increase satisfaction with the supervisor and coworkers, enhance perceptions of psychological safety, and increase the likelihood of future prosocial behavior by both the giver and the receiver.

Affection, love, admiration, respect, and compassion. Most workplaces are intensely social, featuring vertical and horizontal relationships with other employees as well as relationships with customers and suppliers. Positive social emotions experienced in connection with these relationships deserve more attention. The need to belong by forming attachments with other people is a powerful, pervasive, and fundamental human motivation, the satisfaction of which is consistently associated with positive psychological and physiological outcomes, and the frustration of which is often detrimental to well-being (Baumeister \& Leary, 1995).

The positive organizational scholarship movement has emphasized, among other things, the importance of high quality connections at work, be they brief contacts with others or sustained supportive and respectful relationships (e.g. Dutton \& Ragins, 2007; Heaphy \& Dutton, 2008). While most of the small relatively amount of work on positive social emotions at work 
considers relatively stable relationships (e.g. leader-member exchange, workplace friendship networks, mentoring, etc.), it is possible that more fleeting interpersonal affective events which generate short term positive emotions are also important in creating longer term well-being. It is time to go beyond the rather pallid chronic constructs of satisfaction with leaders and coworkers to explore positive social emotions such as liking, love, respect, and admiration experienced in connection with work activities.

There is very little research on feeling respect or admiration toward others, or on feeling respected or admired by others. Grover (2014) has written about respect in organizations, suggesting that is it relevant to understanding leadership, engagement, turnover, interactional fairness, group dynamics, and reputation. Carmeli, Dutton, and Hardin (2015) have suggested that "respectful engagement" with colleagues fosters creativity at least partly through positive emotions such as appreciation and gratitude.

Admiration seems a useful, probably common, but almost entirely neglected positive emotion in the workplace. Schindler, Zink, Windrich, and Menninghaus (2012) suggest that admiration should have four action tendencies: to give praise to the admired party’s skills, virtues, or accomplishments, to affiliate with the admired party, to internalize the values and goals of the admired party, and to imitate the admired party. The long-term adaptive function of admiration is to transmit knowledge and values through social learning. Evidence for selfexpansion as a consequence of admiration through the action tendency of emulation is provided by Schindler, Paech, and Löwenbrück (2015).

Dutton, Workman, and Hardin (2014) make a case for the importance of compassion in organizations. Compassion occurs when one person feels empathic concern/sympathy and responds with altruistic caring to another who is suffering, clearly suggesting an emotionally 
charged interpersonal interaction between the giver and receiver of compassion. The outcomes of compassionate action can be improved positive emotions for both giver and receiver. Compassion may also trigger feelings of gratitude in the beneficiary.

Guilt. Guilt is a “moral emotion” felt when one becomes aware of having violated important social norms. The action tendency for guilt is to engage in reparatory behavior such as apologizing or changing one’s behavior to make amends. Ilies et al. (2013) demonstrated that providing feedback to employees on their level of counterproductive work behavior induced feelings of guilt, and that guilt fully mediated the relationship between feedback and subsequent organizational citizenship behavior. In sum, drawing attention to falling short of a social norm seems to be an effective way, though the emotion of guilt, to motivate employees to lift their game.

Contempt. Contempt is beginning to receive attention from organizational scholars. It is a social emotion involving “distancing expressions of superiority, condescension, disapproval, and exclusion” which may be communicated verbally or by demeaning expressions such as eyerolling or raising one lip corner (Melwani \& Barsade, 2011 pp. 503-504). “Contempt arises when a person's or group's character is appraised as bad and unresponsive to change, leading to attempts to socially exclude the target” (Fischer \& Giner-Sorolla, 2016). The function of contempt seems to be to increase social distance and reduce the social status of the recipient. Contempt is organizationally relevant because it accompanies the judgement that another is incompetent (Hutcherson \& Gross, 2011), and the workplace offers many formal and informal opportunities to compare performance or judge the competence of others. Being on the receiving end of contempt can have severe effects. Gottman’s (1993) seminal work on marital stability vs. breakdown implicated contempt (along with criticism, stonewalling, and defensiveness) as a key 
predictor of divorce. Melwani and Barsade (2011) present three laboratory studies demonstrating that contemptuous (vs. angry vs. neutral) feedback reduced self-esteem and caused recipients to work harder in subsequent rounds (unless they were of higher status than the sender of contempt), to display more aggression toward the sender of contempt (unless they were of lower status), and to experience reciprocal feelings of contempt toward the sender.

The expression of contempt is likely to be a common feature of bullying and abusive supervision. However, looking down on another may also signal that the source of the emotional display is of higher status and is more "leader-like.” Melwani, Mueller, and Overbeck (2012) report three studies showing that displays of both contempt and compassion positively predicted leader emergence. These emotions operate through viewer perceptions that the displayer is more intelligent and therefore a closer match to the leader prototype. Note that the display of four emotions that do not convey information about relative social status (anger, envy, admiration, and love) did not predict leader emergence in these studies. Note also that these results may be culture-bound if expectations of appropriate leader behavior vary.

It has been suggested that contempt from one employee toward another may be an outcome of social-comparison-based pride (Buechner et al., 2016). However, Tse, Lam, Lawrence, and Huang (2013) found that contempt from one co-worker to another can also be felt when the co-workers have unequal leader-member exchange relationships with their shared leader, regardless of whether the party feeling contemptuous has the better or the worse relationship.

Anger. Anger has attracted more attention from organizational researchers than any other negative emotion. A review of anger in organizations is offered by Gibson and Callister (2010), so this section will be brief. Anger is a "basic" emotion. It is a common response to intentional 
mistreatment, injustice, goal blockage, or misbehavior by another person or entity. The action tendency for anger is often to somehow attack the entity that is blamed, in an effort to retaliate or put right the wrong (Lazarus, 1991).

Most research focus to date has been on the harmful effects of anger expression, from incivility to violence and the destruction of relationships (Chervonsky \& Hunt, 2017), but functional and adaptive consequences are also possible. Anger expression may result in the expresser being more likely to have his or her needs met and injustices brought to light and remedied (e.g. Kirrane, O’Shea, Buckley, Grazi, \& Prout, 2017; Lebel, 2017; Stickney \& Geddes, 2014). Anger may be suppressed, expressed in a controlled and lower intensity form than the internal experience, or expressed authentically exactly as felt. Positive outcomes seem most likely when the anger expression is perceptible but below the "impropriety threshold” set by norms for that situation (Geddes \& Callister, 2007). Anger also plays a role in negotiation, influencing the behavior of both target and expresser (e.g. Allred et al., 1997; Van Kleef \& Côté, 2007).

Boredom. Boredom is “the aversive experience of having an unfulfilled desire to be engaged in a satisfying activity” (Fahlman, Mercer-Lynn, Flora, \& Eastwood, 2013, p. 80) or alternatively it is feeling unchallenged and perceiving one’s current activity as meaningless (Van Tilburg \& Igou, 2012). It is commonly experienced at work, even by white collar and professional employees. The adaptive purpose of boredom is to motivate exploration and goal change toward more rewarding activities when the current situation is not satisfying (Bench \& Lench, 2013), yet this may not be possible given the constraints of many work environments. Bored employees may distract themselves with non-task-related thoughts, horseplay, gossip, cyberloafing, or other unproductive activities, and boredom is associated with mind wandering 
and reduced performance on vigilance tasks. On the other hand, some bored employees seek additional work or learning opportunities, engage in citizenship behavior, or when possible manage their boredom by shifting between tasks. Reviews of boredom at work are available from Cummings, Gao, and Thornburg (2016), Fisher (in press), and Loukidou, Loan-Clarke, and Daniels (2009).

Envy, jealousy, and schadenfreude. Envy appears to be a common phenomenon in the workplace, especially given a general human penchant for social comparison, the competitive nature of many workplaces, and the necessary rationing of valuable rewards and status in hierarchical organizations. Envy arises when another receives something one wants but does not receive (e.g., a raise, a promotion, recognition, or any other tangible or intangible advantage), possibly accompanied by the implicit loss of relative social status and perceptions of injustice. There may be two forms of envy, malicious and benign, and in fact the Dutch language has different words for these and no word for envy in general (Van de Ven, 2017).

Envy is considered to be one of the seven deadly sins, and it is generally not acceptable to express this feeling publicly. Hence, those feeling envy may resort to covert actions in the form of counter-productive work behavior aimed at the more favoured party such as undermining, sabotage, lack of cooperation, or spreading rumours (Khan, Quratulain, \& Bell, 2014; Viega, et al., 2014). Malicious envy is especially likely to lead to dysfunctional efforts to tear down the favoured party, whereas benign envy may lead to attempts to improve one’s own performance toward the standard set by the favoured party (Van de Ven, 2017; Van de Ven et al., 2015). A construct similar to malicious envy, jealousy, is negatively related to organizational citizenship behavior (Wang \& Sung, 2016). 
Schadenfreude is the positive emotion of feeling of pleasure in response to another's misfortune, failure, or suffering. It is considered in poor taste to share/display this emotion, unless the misfortunate party clearly deserved their fate due to an unethical act, in which case the social sharing of schadenfreude among observers may serve the purpose of reinforcing the norms that were violated (Dasborough \& Harvey, 2017).

\section{Emotion Expression and Regulation}

I have discussed a number of specific emotions that individuals may feel in the workplace. However, individuals are not slaves to their emotions and often actively manage either what they feel or what they express. The next sections discuss the means and outcomes of emotion expression and regulation as they may play out at work.

\section{Emotion Expression}

The interpersonal effects of emotion depend on their display and interpretation by interaction partners or observers. Van Kleef's (2010) Emotions as Social Information (EASI) model points out the key role of displayed emotions in communicating with others. One party's emotional display may almost automatically evoke the same or a related feeling in another party via contagion, e.g. anger evokes anger or fear. Alternatively, one party's emotional display may induce a more systematic inference process in the other which results in the other experiencing quite a different emotion and carefully choosing a response accordingly. An example of the second process, inference, might be that a display of happiness from a negotiation partner is interpreted as meaning that no further concessions are needed (see Van Kleef, 2014, for more examples). Whether automatic or inferential processes predominate in a given exchange is hypothesized to depend on factors such as the inappropriateness and intensity of the emotional display and the motivation to engage in careful information processing. 
Further evidence for the social influence of expressed emotions comes from research on emotion cycles or spirals, as described by Hareli and Rafaeli (2008). Expressed emotions influence targets of those emotions as well as observers, and may elicit a range of emotions and behaviors in return that subsequently influence the initial displayer. Groth and Grandey (2012) describe how service provider - customer interactions can turn into negative exchange spirals. Andersson and Pearson’s (1999) classic piece, “Tit for Tat? The Spiralling Effect of Incivility in the Workplace,” describes similar spirals among peers. More recently, Foulk, Woolum, and Erez (2016) published “Catching Rudeness is Like Catching a Cold: The Contagion Effects of Lowintensity Negative Behaviors.” While cognitive explanations play a role in these phenomena, there can be little question that experienced and expressed emotions would also be heavily involved in escalating cycles of incivility or rudeness.

Expressing positive emotions is generally beneficial for social outcomes (Chervonsky \& Hunt, 2017), with the possible exception of expressing too much pride (Kalokerinos et al., 2014). Expressing or sharing affective events and associated feelings with one or more coworkers can also have intrapersonal effects on the expresser. One study found that sharing positive work events and feelings with others almost always amplified positive feelings, while sharing negative work events and feelings mitigated negative feelings in 70\% of cases (Hadley, 2014).

\section{Emotion Regulation}

Individuals often try to regulate their emotions to make themselves feel better by downregulating negative emotions and up-regulating positive emotions. Because emotions also communicate to others (e.g. Van Kleef, 2014), have social impacts, and can feed or moderate emotional spirals in dyads (Hareli \& Rafaeli, 2008), individuals may also be motivated to control the emotions they display to others. A flood of research on emotion regulation was unleashed by 
Gross’ seminal (1998) review, in which he presented the Process Model of Emotion Regulation. The model explains how emotions emerge over time and the points at which different emotions regulation strategies may be used, either prior to the experience of a potential emotion or after the emotion is already being felt. Emotions are reactions to current situations, so early regulation opportunities occur in the selection or modification of situations to change the likelihood of a particular emotional experience occurring in the first place. For instance, one might choose to skip a meeting likely to induce boredom. In the next stage, attention deployment may be used to direct attention toward specific aspects of the situation or to distract one's focus away from distressing elements, so the emotion is not experienced or is less intense. A bored meeting attendee might choose to doodle or plan their weekend rather than pay attention to the discussion in progress. In addition, cognitive change, most often reappraisal, may be used to change the meaning of the situation in the desired direction. In this strategy, the attendee may convince themselves that the topic of the meeting is important and relevant to them so they feel less bored. Finally, response modulation involves attempting to regulate the display and action tendencies associated with the emotion being experienced. The bored meeting attendee might inhibit their desire to yawn or fidget and instead pretend to be paying attention.

There is a very large literature on emotion regulation strategies in clinical and social psychology. The vast majority of this literature focuses on the down-regulation of negative emotions. Meta-analyses suggest that activities that distract attention from a negative affective state are generally effective in improving affect. Problem-focused coping responses which modify the situation are also helpful, as are attempts to reappraise the situation so it appears less negative (Aldao, 2010; Augustine \& Hemenover, 2009; Chervonsky \& Hunt, 2017; Webb, Miles, \& Sheeran, 2012). 
Diefendorff, Richard, and Yang (2008) explored the strategies that employees said they used to regulate negative emotions at work. The most frequent emotions triggering the need to regulate were annoyance, frustration, and anger. The most commonly used strategies were seeking out individuals that make one feel good, keeping busy working on other things, doing something enjoyable, trying to solve the problem, finding humour in the situation, and thinking about how the other person feels. The least used strategies were avoiding a situation that will cause bad feelings and leaving the situation, perhaps because these are often not available options given the constraints and expectations of work roles.

Emotion down-regulation and suppression. Suppression is the active inhibition of the experience or expression of an emotion that is being felt. A recent meta-analysis concluded that, “greater suppression of emotion was significantly associated with poorer social well-being, including more negative first impressions, lower social support, lower social satisfaction and quality, and poorer romantic relationship quality (Chervonsky \& Hunt, 2017, p. 669;). Suppression requires effort and consumes resources that might otherwise be available for task performance. The rationales for the negative impact of surface acting on well-being involve the costs of suppression and resulting inauthenticity and emotional dissonance between what is felt and what is displayed to customers. Two field studies of the naturally occurring use of emotion suppression during the pursuit of personally important goals showed that suppression reduced future goal effort, goal competence, and goal success. Suppression was also associated with subsequent negative moods and lowered social support, suggesting that frequent or sustained suppression may not generally be a desirable strategy for employees (Low, Overall, Hammond, \& Girme, 2017). 
On the other hand, there clearly is a role for occasional suppression of emotional displays in the interest of getting along in a complex social world. As mentioned before, partial suppression of anger displays to remain below the impropriety threshold is socially beneficial (Geddes \& Callister, 2007). Part of the supervisor's role is to help subordinates regulate their emotions, and suppression may be a tactic they suggest. One study showed that when an empathic supervisor (“I understand your justified anger at what someone else has done to you”) recommended a suppression strategy ("let's put it behind us, think positively, and put your considerable skills to work”) following an unfair event, employee stress was minimized (Thiel, Griffith, \& Connelly, 2015).

Emotion up-regulation - rumination and savoring. Another form of regulating experienced emotions involves intentionally amplifying their intensity or duration. Generally individuals seek pleasure and avoid pain, so the up-regulation of positive emotions, should be more common than the up-regulation of negative ones. However, a disproportionate share of research has concentrated on the latter in the form of rumination (Smith \& Alloy, 2009). Rumination is persistently thinking about a negative event or feeling, its causes, and the distress one is experiencing in consequence. It is strongly implicated in the development of depression and anxiety disorders (Nolen-Hoeksema, Wisco, \& Lyubomirsky, 2008; Olatunji, NaragonGainey, \& Wolitzky-Taylor, 2013). On a smaller scale, replaying negative work events has also been shown to be harmful. Wang et al. (2013) found that post-work rumination about being mistreated by customers predicted negative mood the next morning. They suggested that organizations should help their employees avoid rumination by encouraging them to engage in mastery activities after work (e.g. hobbies, volunteer work) as well as training them in service recovery and enhancing perceived organizational support. 
Quoidbach, Mikolajczak, and Gross (2015) point out a huge recent boom in research on the up-regulation of positive emotions such as joy, pride, excitement, and awe, with the aim of increasing life happiness. Positive interventions aimed at this purpose will be discussed further in a later section of this paper. One way to up-regulate positive emotions is called savoring more or less the opposite of rumination. "Savoring involves the self-regulation of positive feelings, most typically generating, maintaining, or enhancing positive affect by attending to positive experiences from the past, present, or future” (Bryant, Chadwick, \& Kluwe, 2011 p. 108). Individuals can savor positive emotions by consciously focusing on feelings about a pleasant event as it is unfolding in real time, by reminiscing about positive feelings, activities, and accomplishments from the past, and by thinking about and anticipating future positive feelings. Savoring helps intensify, prolong or reactivate positive emotional experiences and therefore helps individuals more fully reap the benefits of positive affect. Self-reported savoring of positive emotions is positively related to positive affect and to resilience, as would be predicted by Fredrickson’s Broaden-and-Build model (Sharna, Desiree, \& Stephen, 2015). Instructions to reminisce about a positive event 10 minutes per day for a week increased the percent of time people felt happy (Bryant, Smart, \& King, 2005). There is also evidence that savoring has beneficial effects on cortisol (a physiological marker of stress) and activates regions of the brain involved in processing rewards and positive emotions (Speer \& Delgado, 2017).

Savoring seems beneficial but may be under-used. In an article entitled, “It Ain’t Over 'Til It’s Over,” Schall, Goetz, Martiny, and Hall (2017) report three studies showing that individuals are cautious about savoring interim successes on the road to a final goal. Savoring of interim accomplishments was inhibited by worries about the tasks yet to come or the belief that celebrating too soon would undermine, or at least not facilitate, future motivation and success. 
Intentional savoring was more likely to occur after the entire task was completed to an above average standard, though individuals did not go so far as to actively suppress positive feelings about interim accomplishments. Schall et al. (2017) suggest that there may be motivational and well-being benefits from taking greater advantage of opportunities to savor while tasks are still in progress.

\section{The Future of Research on Emotions at Work}

It seems likely that emotions will continue to attract considerable research attention from organizational scholars. The methods used and sophistication of research questions have developed over time, as discussed briefly below. A particular arena for future research is the study of positive emotions, including the design of effective interventions to enhance positive emotions at work.

\section{Methods for Studying Emotions at Work}

Studying emotions is often best served by methods which permit the assessment of situations/events, emotions, cognitions, and behavior in real time. Fortunately, experience sampling (Fisher \& To, 2012) and diary methods are available to capture within-person processes and enable the study of emotional dynamics over short periods of time. Advances in technology have made these methods much more accessible and they have been widely adopted (e.g. Beal, 2015; Mehl \& Conner, 2011). Repeated measures also allow the investigation of emotional processes that go beyond the immediate experience of a "hot" emotion to somewhat delayed effects, such as next morning affect or recovery (e.g. Wang et al., 2013). One might expect that the experience of particularly intense emotions (e.g. strong anger, fear, or joy) would last well beyond the relatively brief physiological response. Thinking about an affective event

and how one felt (rumination or savoring) is also likely to prolong or reactivate the emotion and 
increase the duration of its effect. We know little about when and why individuals use rumination or savoring at work, though it is probably quite common. Continued use of experience sampling and diary methods to study these and other within-person emotional processes over time is recommended.

A novel approach is even more fine grained and may be useful for some laboratory studies of emotions. Continuous rating assessment (CRA) involves participants using a slider to indicate what they were feeling or thinking several times per second as they review a recent affective event on videotape. CRA permits the capture of responses to micro-events within events, e.g. when a call center customer turns from pleasant to rude or back, or when deep acting becomes surface acting. This allows for assessing the time dynamics and topology of change in real time, as well as assessing the effects of peak, valley, and end states on perceptions of an affective event as a whole (Gabriel \& Diefendorff, 2015; Gabriel, Diefendorff, Bennett, \& Sloan, 2017).

\section{Consequences of Emotions at Work}

The field has moved away from a knee-jerk view of the effects of emotions via their action tendencies to a more sophisticated, nuanced, and contingent view of how emotions contribute to behavior. Scholars are building theory involving mediators and moderators of the processes by which emotions have effects. We are also coming to understand the ways in which emotions of either valence can have symmetric or asymmetric consequences depending on a host of individual and situational factors. Such sophisticated thinking should continue. One example is a conceptual piece by Tai et al., (2012), who theorize about how interpersonal behavior and job performance may be impacted by feelings of envy, contingent upon attributes of the perceiver, the target, and the surrounding organizational context. Envy leads to attempts to relieve discomfort and restore balance by getting even or by getting ahead. That is, individuals may act 
to undermine the targets of their envy, or alternatively view them as a challenging role model and strive to emulate their success. Tai et al. (2012) suggest that less undermining and greater performance will occur when perceiver core self-evaluations are high, the target of envy is seen as both warm and competent, and organizational support is high.

Another example of sophisticated thinking about the contingent effects of discrete emotions is provided by Conroy, Becker, and Menges (2016). They hypothesized and investigated the effects of feelings of anger, guilt, and pride on turnover intentions as a function of relative strength of organizational and occupational identification. Anger, guilt, and pride were negatively associated with turnover intentions when organizational identification was high and positively related when organizational identification was low, and these effects were moderated by occupational identification. They concluded that "when identifications are considered, the effects of discrete emotions can differ among emotions with similar valence (e.g. anger and guilt), and be similar for emotions with different valence (e.g., guilt and pride)” (Conroy et al., 2016, p. 1087).

\section{Positive Emotion Interventions}

I have made the case that a number of discrete emotions of both valences should attract more attention from organizational scholars, and that positive emotions are the most understudied in the workplace. While not all positive emotions produce positive organizational outcomes, and some negative emotions can produce beneficial effects, on the whole an increase in the experience of positive emotions at work should be beneficial for employee well-being and probably will produce positive consequences for organizations as well, whether directly or via employee well-being (Lyubomirsky et al., 2005; Tenney, Poole, \& Diener, 2016). Writing in Psychological Bulletin, Quoidbach et al. (2015, p. 655) conclude that, “There is now strong 
evidence that positive emotions are worth cultivating, not only as ends in themselves but also as a means of achieving success and psychological growth, improved mental and physical health, more satisfying and lasting social and marital relationships, and even positive societal changes.”

In the workplace, we know that naturally occurring daily variation in positive emotions is related to concurrent desirable outcomes such as engagement (Ouweneel, Le Blanc, Schaufeli, \& Van Wijhe, 2012), creativity (e.g. To, Fisher, Ashkanasy, \& Rowe, 2012), and citizenship behavior (e.g. Ilies, Scott, \& Judge, 2006), to name just a few. Over time, more frequent positive emotions should cumulate to influence individual attitudes, group affective tone, and organizational affective climate. It seems reasonable for organizations and individuals to try to increase the occurrence of positive emotions at work. Guidance on how this might be accomplished has been taken from the explosion of research on "positive interventions” designed to increase happiness in general. Reviews of this work conclude that while it is relatively difficult to create consistent and sustained increases in overall life happiness, perhaps due to genetic set points or adaptation level phenomena, modest change can occur with effort and the regular use of happiness-enhancing activities (Bolier et al., 2013; Sheldon, Boehm, \& Lyubomirsky, 2013; Sin \& Lyubomirsky, 2009). The most effective positive interventions seem to target three pathways to building happiness: increasing positive emotions, increasing engagement, and increasing meaning (Parks \& Layous, 2016; Parks, Schueller, \& Tasimi, 2013). All three of these are potentially manipulable and relevant at work.

The observation by Spreitzer, Sutcliffe, Dutton, Sonenshein, and Grant in 2005 that more is known about reducing stress and disease than about cultivating thriving at work is still true. Admittedly, "bad is stronger than good” (Baumeister et al., 2001), and most interventions to date have been aimed at helping employees manage negative emotions in chronically stressful jobs 
(e.g., Buruck, Dorfel, Kugler, \& Brom, 2016; Cheng et al., 2015). However, there have been some reports of interventions design specifically to increase positive emotional states among employees, with mixed to modest success. Meyers, Van Woerkom, and Bakker (2013) provide a narrative review of 15 varied positive organizational interventions. Most interventions had a beneficial impact on at least one positively toned affective outcome and some interventions reduced stress, though only few reduced negative affect.

Gratitude treatments seem to be the most consistently effective in the general life happiness literature as well as in organizational applications to date (Winslow, Kaplan, Bradley-Geist, Lindsey, Ahmad, \& Hargrove, 2017). Fehr et al. (2016) suggest that organizations can enhance the experience of gratitude by adopting peer-recognition programs which encourage employees to express gratitude to others in the organization, by increasing contact with the beneficiaries of employees’ work who may express gratitude, and by providing supportive feedback and mentoring so that employees feel gratitude towards the organization or their supervisor. Neumeier, Brook, Ditchburn, and Sckopke (2017) found that two on-line daily programs were equally effective in increasing overall and work-related well-being compared to a wait-listed control group. The successful conditions were a gratitude treatment and another based on Seligman’s (2011) five component approach to well-being emphasizing positive emotions, engagement/interest in life activities requiring one’s strengths, satisfying personal relationships, meaning, and accomplishment/mastery. Another study compared a gratitude intervention to a social connectedness intervention (exhortations to talk to a colleague personally rather than send an email, or go to coffee with them) and found that both reduced sickness-related absence and that the gratitude intervention increased positive affective well-being. However, the social connectedness intervention did not increase positive affect, and neither intervention reduced 
negative affect (Kaplan, Bradley-Geist, et al., 2014). Winslow et al. (2017) compared a waitlisted control group to a workplace gratitude intervention to a group which alternated gratitude with a social connectedness activity. Neither intervention was effective across the board, though individual differences in agreeableness, conscientiousness, and tenure moderated the effect of the gratitude intervention on some outcomes.

Bono, Glomb, Shen, Kim, and Koch (2013) assessed the effect of a positive daily reflection intervention (write about three good things that happened today) on well-being in the evening. While effects were small, they were significant, with stress and health complaints being lower on evenings following positive reflections. A similar intervention was ineffective in a study by Meier, Cho, and Dumani (2016). Likewise, a half day training program intended to enhance job crafting was unsuccessful in building employee positive affect (Van den Heuval, Demerouti, \& Peeters, 2015), and several other studies have found quite small or nonsignificant effects of positive interventions (e.g. Meier et al., 2016; Muller, Heiden, Herbig, Poppe, \& Angerer, 2016).

While meta-analyses have confirmed that positive interventions can be somewhat effective in alleviating depression and increasing life happiness among those who embrace this goal, convincing evidence of the effectiveness, lasting impact, and utility of specific positive emotional interventions in the workplace is still insufficient to guide practice. It is unclear what the most effective interventions might be, whether they work equally well for everyone, whether there is a need to regularly change the intervention/activities to avoid hedonic adaptation, and what the optimal frequency might be (Lyubomirsky, Sheldon, \& Schkade, 2005).

Perhaps organizational scholars have been too eager to adopt interventions designed to counter depression and increase well-being in a general population. Such add-on interventions 
may be seen as irrelevant or inappropriate in the workplace. For instance, Winslow et al. (2017) found that more conscientious employees reported reductions in positive emotions following the positive intervention, perhaps seeing it as a waste of time which took attention away from "real work.” Another caution about positive interventions concerns the right of organizations to attempt to “mess with” their employees’ minds. Some positive interventions, unless entirely voluntary, would fall outside the normal psychological contract of exchange between employee and employer and could even be seen as attempts at brain-washing. Especially problematic are organizationally sponsored interventions that recommend unpaid off-the-job activities such as undertaking non-job-related mastery activities or encouraging positive work-related reflection in the evening (Wang, et al., 2013).

Research on positive emotions in organizations in particular may offer insights into less contrived interventions which may be more effective for normally well-adjusted adults in the workplace. Research by Amabile and Kramer (2007; 2011) provides some suggestions. They analyzed employee diary reports of one major (affective) event per day to discover the correlates of happy days vs bad days. They found that happy days were characterized by perceived progress and accomplishment on meaningful work tasks, and bad days by setbacks on tasks. They concluded that the most useful managerial activities to build a positive "inner worklife" (positive emotions, beliefs, and motivation) among employees were to assure clear and achievable goals which enabled small wins on meaningful work tasks, to remove roadblocks, and to treat employees with genuine care, consideration, and appreciation. Returning to the list of oftenignored positive emotions at work discussed earlier in this chapter, the meaningful work and achievable short-term goals Amabile and Kramer (2007; 2011) recommend should enhance interest, authentic pride, and the opportunity to savor past and current successes. Ohly and 
Schmitt (2015) developed a taxonomy of positive and negative work events that is quite consistent with Amabile and Kramer's suggestions. They found that $92 \%$ of positive affective events reported by employees could be clustered into three categories related to goal attainment/solving a problem/task-related success, praise and positive feedback, and social competence. Thirty nine percent of negative work events had to do with goal blockages or technical difficulties with work equipment. These findings corroborate the importance of perceived and recognized performance for positive vs negative emotions at work (Fisher, 2008). Interventions aimed at perceptions of progress and competence might be more effective in building positive emotions in the workplace than those aimed at gratitude. They are also more likely to be seen as legitimate by employees, and to enhance performance directly as well as indirectly via employee well-being. Research is needed to develop, test, and compare different types of positive interventions suited to the workplace context.

At the organizational level, affective climate could be a focus of attention. Parke and Seo (2017) discuss how organizations might create affective climates that encourage the actual experience and authentic display of positive emotions, or that permit the experience and authentic display of both positive and negative emotions. These climates are hypothesized to be generally better for a range of performance outcomes than those which focus on negative emotions exclusively, or on the suppression of authentic emotions in order to provide organizationally mandated displays.

\section{Conclusions}

The experience of discrete emotions of both positive and negative valence is endemic to the workplace. The unique appraisal patterns and action tendencies associated with each emotion gives these affective phenomena explanatory power beyond that provided by moods. A 
wide variety of different emotions exist, and a great many of them are likely to be experienced in the workplace. A theme throughout this chapter has been the relative dearth of research and importance accorded to positive emotions compared to negative emotions. Granted, negative emotions are more likely to trigger specific action in an attempt to remedy a situation in which personal interests are at risk, and negative emotions probably have clearer immediate implications for behavior at work. Nevertheless, positive emotions, their effects, and their cultivation represent a useful field for future research enquiry with the very real possibility of improving quality of life in organizations as well as organizational outcomes. In this regard, interventions targeted more specifically to workplace realities and priorities may be more effective than those borrowed from the general positive psychology literature.

Several topics relevant to emotions in organizations were not addressed in this chapter due to lack of space, but it seems imprudent to close without mentioning their potential effects. One topic involves individual differences in emotional competencies or emotional intelligence which may have both intrapersonal effects on how individuals feel and react to affective events as well as interpersonal effects on how they relate to others. While there are still debates about measurement and overlap with existing constructs, emotional intelligence does predict organizationally important outcomes such as performance, conflict resolution, attitudes, and leadership (e.g. Joseph, Jin, Newman, \& O'Boyle, 2015; Miao, Humphrey, \& Qian, 2017; Schlaerth, Ensari, \& Christian, 2013; Walter, Cole, \& Humphrey, 2011). A related issue is the existence of trait forms of many emotions including anger, boredom, fear, anxiety, contemptuousness, gratitude, and pride. Trait tendencies reflect the greater likelihood of some people experiencing particular emotions, or experiencing them more intensely, given any reason to do so. Measures of a number of these trait emotional tendencies have been developed. 
Individual differences in emotional intelligence and traits may have relevance for employee selection as well as responsiveness to particular affective events or interventions. In short, there is much to be learned about discrete emotions at work, and much to be gained from the effort to do so.

\section{References}

Aldao, A., Nolen-Hoeksema, S., \& Schweizer, S. (2010). Emotion-regulation strategies across psychopathology: A meta-analytic review. Clinical Psychology Review, 30(2), 217-37. doi: 10.1016/j.cpr.2009.11.004

Algoe, S. B., Fredrickson, B. L., \& Gable, S. L. (2013). The social functions of the emotion of gratitude via expression. Emotion, 13(4), 605-609. doi:10.1037/a0032701

Allred, K. G., Mallozzi, J. S., Matsui, F., \& Raia, C. P. (1997). The influence of anger and compassion on negotiation performance. Organizational Behavior and Human Decision Processes, 70(3), 175-187. doi://doi.org/10.1006/obhd.1997.2705

Amabile, T., \& Kramer, S. (2007). Inner work life: Understanding the subtext of business performance. Harvard Business Review, 85(5), 72-83, 144.

Amabile, T., \& Kramer, S. (2011). The power of small wins. Harvard Business Review, 89(5), 70-80.

Andersson, L. M., \& Pearson, C. M. (1999). Tit for tat? The spiraling effect of incivility in the workplace. Academy of Management Review, 24(3), 452-471.

doi:10.5465/AMR.1999.2202131

Ashkanasy, N., \& Dorris, A. D. (2017). Emotions in the workplace. Annual Review of Organizational Psychology and Organizational Behavior, 4, 67-90. doi:10.1146/annurevorgpsych-032516-113231 
Ashforth, B. E., \& Humphrey, R. H. (1995). Emotion in the workplace: A reappraisal. Human Relations, 48(2), 97-125. doi:10.1177/001872679504800201

Augustine, A. A., \& Hemenover, S. H. (2009). On the relative effectiveness of affect regulation strategies: A meta-analysis. Cognition and Emotion, 23(6), 1181-1220. doi:10.1080/02699930802396556

Averill, J. R. (1980). On the paucity of positive emotions. In K. Blankstein, P. Pliner, \& J. Polivy (Eds.), Advances in the study of communication and affect: Vol. 6. Assessment and modification of emotional behavior (pp. 7-45). New York: Plenum.

Barsade, S. G., Brief, A. P., \& Spataro, S.E. (2003). The affective revolution in organizational behavior: The emergence of a paradigm. In J. Greenberg (Ed.) Organizational behavior: The state of the science (2nd ed., pp. 3-52). Mahwah, NJ: Lawrence Erlbaum.

Barsade, S. G., \& Knight, A. P. (2015). Group affect. Annual Review of Organizational Psychology and Organizational Behavior, 2, 21-46. doi:10.1146/annurev-orgpsych032414-111316

Basch, J. \& Fisher, C. D. (2000). Affective job events - emotions matrix: A classification of job related events and emotions experienced in the workplace. In N. Ashkanasy, W. Zerbe, \& C. Hartel (Eds.), Emotions in the workplace: Research, theory, and practice (pp. 36-48). Quorum Books.

Baumeister, R. F., Bratslavsky, E., Finkenauer, C., \& Vohs, K. D. (2001). Bad is stronger than good. Review of General Psychology, 5(4), 323-370. doi: 10.1037//1089-2680.5.4.323

Baumeister, R. F., \& Leary, M. R. (1995). The need to belong: Desire for interpersonal attachments as a fundamental human motivation. Psychological Bulletin, 117(3), 497-529. doi:10.1037/0033-2909.117.3.497 
Baumeister, R. F., Vohs, K. D., DeWall, C. N., \& Zhang, L. (2007). How emotion shapes behavior: Feedback, anticipation, and reflection, rather than direct causation. Personality and Social Psychology Review, 11(2), 167-203. doi:10.1177/1088868307301033

Beal, D. J. (2015). ESM 2.0: State of the art and future potential of experience sampling methods in organizational research. Annual Review of Organizational Psychology and Organizational Behavior, 2, 383-407. doi:10.1146/annurev-orgpsych-032414-111335

Bench, S. W., \& Lench, H. C. (2013). On the function of boredom. Behavioral Sciences, 3, 459-472. doi://dx.doi.org/10.3390/bs3030459

Bolier, L., Smit, F., Haverman, M., Westerhof, G. J., Bohlmeijer, E., \& Riper, H. (2013). Positive psychology interventions: A meta-analysis of randomized controlled studies. BMC Public Health, 13, 119. doi:10.1186/1471-2458-13-119

Bono, J. E., Glomb, T. M., Shen, W., Kim, E., \& Koch, A. J. (2013). Building positive resources: Effects of positive events and positive reflection on work stress and health. Academy of Management Journal, 56(6), 1601-1627. doi:10.5465/amj.2011.0272

Brown, C. M., \& McConnell, A. R. (2011). Discrepancy-based and anticipated emotions in behavioral self-regulation. Emotion, 11(5), 1091-1095. doi: 10.1037/a0021756

Bryant, F. B., Chadwick, E. D., \& Kluwe, K. (2011). Understanding the processes that regulate positive emotional experience: Unsolved problems and future directions for theory and research on savoring. International Journal of Wellbeing, 1, 107-126. doi:10.5502/ijw.v1i1.18

Bryant, F. B., Smart, C., \& King, S. (2005). Using the past to enhance the present: Boosting happiness through positive reminiscence. Journal of Happiness Studies, 6(3), 227-260. doi:10.1007/s10902-005-3889-4 
Buechner, V. L., Pekrun, R., \& Lichtenfeld, S. (2016). The achievement pride scales (APS). European Journal of Psychological Assessment. doi:10.1027/1015-5759/a000325

Buruck, G., Dorfel, D., Kugler, J., \& Brom, S. S. (2016). Enhancing well-being at work: The role of emotion regulation skills as personal resources. Journal of Occupational Health Psychology, 21(4), 480-493. doi:10.1037/ocp0000023

Carmeli, A., Dutton, J., \& Hardin, A. (2015). Respect as an engine for new ideas: Linking respectful engagement, relational information processing and creativity among employees and teams. Human Relations, 68(6), 1021-1047. doi:10.1177/0018726714550256

Carver, C. S., Sinclair, S., \& Johnson, S. L. (2010). Authentic and hubristic pride: Differential relations to aspects of goal regulation, affect, and self-control. Journal of Research in Personality, 44(6), 698-703. doi:10.1016/j.jrp.2010.09.004

Cheng, S., Tsui, P. K., \& Lam, J. H. M. (2015). Improving mental health in health care practitioners: Randomized controlled trial of a gratitude intervention. Journal of Consulting and Clinical Psychology, 83(1), 177-186. doi:10.1037/a0037895

Chervonsky, E., \& Hunt, C. (2017). Suppression and expression of emotion in social and interpersonal outcomes: A meta-analysis. Emotion, 17(4), 669-683. doi:10.1037/emo0000270

Collins, A. L., Lawrence, S. A., Troth, A. C., \& Jordan, P. J. (2013). Group affective tone: A review and future research directions. Journal of Organizational Behavior, 34, S43-S62. doi:10.1002/job.1887

Conroy, S., Becker, W., \& Menges, J. (2016). The meaning of my feelings depends on who I am: Work-related identifications shape emotion effects in organizations. Academy of Management Journal, 60(3), 1071-1093. doi:10.5465/amj.2014.1040 
Cropanzano, R., Dasborough, M., \& Weiss, H. M. (2017). Affective events and the development of leader-member exchange. Academy of Management Review, 42(2), 233258. doi:10.5465/amr.2014.0384

Cummings, M. L., Gao, F., \& Thornburg, K. M. (2016). Boredom in the workplace: A new look at an old problem. Human Factors, 58(2), 279-300. doi:10.1177/0018720815609503

Dasborough, M., \& Harvey, P. (2017). Schadenfreude: The (not so) secret joy of another's misfortune. Journal of Business Ethics, 141(4), 693-707. doi:10.1007/s10551-016-3060-7

Davis, D. E., Choe, E., Meyers, J., Wade, N., Varjas, K., Gifford, A., Quinn, A., Hook, J. N., Van Tongeren, D. R., Griffin, B. J., \& Worthington, E. L. Jr. (2016). Thankful for the little things: A meta-analysis of gratitude interventions. Journal of Counseling Psychology, 63, 20-31. doi:10.1037/cou0000107

De Rivera, J., Possell, L., Verette, J. A., \& Weiner, B. (1989). Distinguishing elation, gladness, and joy. Journal of Personality and Social Psychology, 57(6), 1015-1023. doi:10.1037/0022-3514.57.6.1015

Dickens, L. R. (2017). Using gratitude to promote positive change: A series of meta-analyses investigating the effectiveness of gratitude interventions. Basic and Applied Social Psychology, 39(4), 193-208. doi:10.1080/01973533.2017.1323638

Diefendorff, J. M., Richard, E. M., \& Yang, J. (2008). Linking emotion regulation strategies to affective events and negative emotions at work. Journal of Vocational Behavior, 73(3), 498-508. doi:10.1016/j.jvb.2008.09.006

Diener, E., \& Diener, C. (1996). Most people are happy. Psychological Science, 7(3), 181185. doi:10.1111/j.1467-9280.1996.tb00354.x 
Dutton, J. E., \& Ragins, B. R. (2007). Exploring positive relationships at work: Building a theoretical and research foundation. Mahwah, NJ: Lawrence Erlbaum Associates.

Dutton, J. E., Workman, K. M., \& Hardin, A. E. (2014). Compassion at work. Review of Organizational Psychology and Organizational Behavior, 1, 277-304. doi: 10.1146/annurev-orgpsych-031413-091221

Eberly, M. B., \& Fong, C. T. (2013). Leading via the heart and mind: The roles of leader and follower emotions, attributions and interdependence. The Leadership Quarterly, 24(5), 696-711. doi:10.1016/j.leaqua.2013.05.003

Elfenbein, H. A. (2007). Emotion in organizations. Academy of Management Annals, 1, 315-386. doi:10.1080/078559812

Fahlman, S. A., Mercer-Lynn, K., Flora, D. B., \& Eastwood, J. D. (2013). Development and validation of the multidimensional state boredom scale. Assessment, 20, 68-85. doi:10.1177/1073191111421303

Fehr, R., Fulmer, A., Awtrey, E., \& Miller, J. (2017). The grateful workplace: A multilevel model of gratitude in organizations. Academy of Management Review, 42(2), 361381. doi:10.5465/amr.2014.0374

Fischer, A., \& Giner-Sorolla, R. (2016). Contempt: Derogating others while keeping calm. Emotion Review, 8(4), 346-357. doi:10.1177/1754073915610439

Fisher, C. D. (2008). Emotions in and around performance: The thrill of victory, the agony of defeat. In N. M. Ashkanasy \& C. L. Cooper (Eds.), Research companion to emotion in organizations (pp. 120-135). Cheltenham, UK: Edward Elgar.

Fisher, C. (2002). Antecedents and consequences of real-time affective reactions at work. Motivation and Emotion, 26, 3-30. doi:10.1023/A:1015190007468 
Fisher, C. D. (in press). Boredom at work: What, why, and what then? In D. Lindebaum, D. Geddes, \& P. J. Jordan (Eds). Emotion in management: The functions of emotion at work and how we talk about it. Edward Elgar.

Fisher, C.D. \& To, M.L. (2012). Using experience sampling methodology in organizational behavior. Journal of Organizational Behavior, 33, 865-877. doi: 10.1002/job.1803

Foulk, T., Woolum, A., \& Erez, A. (2016). Catching rudeness is like catching a cold: The contagion effects of low-intensity negative behaviors. Journal of Applied Psychology, 101, 50-67. doi: 10.1037/apl0000037

Fredrickson, B. L. (1998). What good are positive emotions? Review of General Psychology, 2(3), 300-319. doi:10.1037/1089-2680.2.3.300

Gabriel, A. S., \& Diefendorff, J. M. (2015). Emotional labor dynamics: A momentary approach. Academy of Management Journal, 58(6), 1804-1825. doi:10.5465/amj.2013.1135

Gabriel, A. S., Diefendorff, J. M., Bennett, A. A., \& Sloan, M. D. (2017). It’s about time. Organizational Research Methods, 20, 32-60. doi:10.1177/1094428116673721

Geddes, D., \& Callister, R. R. (2007). Crossing the line(s): A dual threshold model of anger in organizations. Academy of Management Review, 32(3), 721-746. doi:10.5465/AMR.2007.25275495

George, J. M., \& King, E. B. (2007). Potential pitfalls of affect convergence in teams: Functions and dysfunctions of group affective tone. In E. A. Mannix, M. A. Neale, \& C. P.Anderson (Eds.), Research on managing groups and teams (Vol. 10, pp. 97123). Greenwich, CT: JAI Press. 
Gibson, D. E., \& Callister, R. R. (2010). Anger in organizations: Review and integration. Journal of Management, 36, 66-93. doi:10.1177/0149206309348060

Gottman, J. M. (1993). A theory of marital dissolution and stability. Journal of Family Psychology, 7, 57-75. doi:10.1037/0893-3200.7.1.57

Grandey, A. A., \& Gabriel, A. S. (2015). Emotional labor at a crossroads: Where do we go from here? Annual Review of Organizational Psychology and Organizational Behavior, 2, 323349. doi:10.1146/annurev-orgpsych-032414-111400

Grandey, A. A., \& Melloy, R. C. (2017). The state of the heart: Emotional labor as emotion regulation reviewed and revised. Journal of Occupational Health Psychology, 22(3), 407422. doi:10.1037/ocp0000067

Grant, A. M., \& Gino, F. (2010). A little thanks goes a long way: Explaining why gratitude expressions motivate prosocial behavior. Journal of Personality and Social Psychology, 98(6), 946-955. doi:10.1037/a0017935

Grant, A. M., \& Wrzesniewski, A. (2010). I won't let you down...or will I? Core selfevaluations, other-orientation, anticipated guilt and gratitude, and job performance. Journal of Applied Psychology, 95, 108-121. doi:10.1037/a0017974

Gross, J. J. (1998). The emerging field of emotion regulation: An integrative review. Review of General Psychology, 2(3), 271-299. doi:10.1037/1089-2680.2.3.271

Groth, M., \& Grandey, A. (2012). From bad to worse. Organizational Psychology Review, 2(3), 208-233. doi:10.1177/2041386612441735

Grover, S. L. (2014). Unraveling respect in organization studies. Human Relations, 67, 27-51. doi:10.1177/0018726713484944 
Hareli, S., \& Rafaeli, A. (2008). Emotion cycles: On the social influence of emotion in organizations. Research in Organizational Behavior, 28, 35-59. doi:10.1016/j.riob.2008.04.007

Heaphy, E. D., \& Dutton, J. E. (2008). Positive social interactions and the human body at work: Linking organizations and physiology. Academy of Management Review, 33, 137162. doi:10.5465/AMR.2008.27749365

Herzberg, F., Mausner, B. \& Snyderman, B. (1959). The motivation to work. New York, NY: John Wiley \& Sons.

Hochschild, A. R. (1983). The managed heart: Commercialization of human feeling. Berkeley: University of California Press.

Horberg, E. J., Kraus, M. W., \& Keltner, D. (2013). Pride displays communicate self-interest and support for meritocracy. Journal of Personality \& Social Psychology, 105, 24-37. doi: $10.1037 / \mathrm{a} 0032849$

Hu, X. X., \& Kaplan, S. (2015). Is "feeling good" good enough? Differentiating discrete positive emotions at work. Journal of Organizational Behavior, 36, 39-58. doi:10.1002/job.1941

Hülsheger, U. R., \& Schewe, A. F. (2011). On the costs and benefits of emotional labor: A metaanalysis of three decades of research. Journal of Occupational Health Psychology, 16(3), 361-389. doi:10.1037/a0022876

Humphrey, R. H., Ashforth, B. E., \& Diefendorff, J. M. (2015). The bright side of emotional labor. Journal of Organizational Behavior, 36(6), 749-769. doi:10.1002/job.2019

Humphrey, R. H., Burch, G. F., \& Adams, L. L. (2016). The benefits of merging leadership research and emotions research. Frontiers in Psychology, 7, 1022. doi:10.3389/fpsyg.2016.01022 
Hutcherson, C. A., \& Gross, J. J. (2011). The moral emotions: A social-functionalist account of anger, disgust, and contempt. Journal of Personality and Social Psychology, 100(4), 719737. doi:10.1037/a0022408

Ilies, R., Peng, A. C., Savani, K., \& Dimotakis, N. (2013). Guilty and helpful: An emotionbased reparatory model of voluntary work behavior. Journal of Applied Psychology, 98(6), 1051-1059. doi:10.1037/a0034162

Ilies, R., Scott, B. A., \& Judge, T. A. (2006). The interactive effects of personal traits and experienced states on intraindividual patterns of citizenship behavior. Academy of Management Journal, 49(3), 561-575. doi:10.5465/AMJ.2006.21794672

Izard, C. E. (1977). Basic emotions, relations among emotions, and emotion-cognition relations. Psychological Review, 99(3), 561-565.

Jordan, P. J., \& Lindebaum, D. (2015). A model of within person variation in leadership: Emotion regulation and scripts as predictors of situationally appropriate leadership. The Leadership Quarterly, 26(4), 594-605. doi:10.1016/j.leaqua.2015.05.004

Joseph, D. L., Jin, J., Newman, D. A., \& O'Boyle, E. H. (2015). Why does self-reported emotional intelligence predict job performance? A meta-analytic investigation of mixed EI. Journal of Applied Psychology, 100(2), 298-342. doi://dx.doi.org/10.1037/a0037681

Kalokerinos, E. K., Greenaway, K. H., Pedder, D. J., \& Margetts, E. A. (2014). Don't grin when you win: The social costs of positive emotion expression in performance situations. Emotion, 14, 180. doi:10.1037/a0034442

Kammeyer-Mueller, J. D., Rubenstein, A. L., Long, D. M., Odio, M. A., Buckman, B. R., Zhang, Y., \& Halvorsen-Ganepola, M. D. K. (2013). A meta-analytic structural model of 
dispositonal affectivity and emotional labor. Personnel Psychology, 66, 47-90.

doi:10.1111/peps.12009

Kaplan, S., Bradley-Geist, J., Ahmad, A., Anderson, A., Hargrove, A., \& Lindsey, A. (2014). A test of two positive psychology interventions to increase employee well-being. Journal of Business and Psychology, 29(3), 367-380. doi:10.1007/s10869-013-9319-4

Kaplan, S., Cortina, J., Ruark, G., LaPort, K., \& Nicolaides, V. (2014). The role of organizational leaders in employee emotion management: A theoretical model. The Leadership Quarterly, 25(3), 563-580

Keltner, D., \& Gross, J. J. (1999). Functional accounts of emotions. Cognition and Emotion, 13(5), 467-480. doi:10.1080/026999399379140

Khan, A. K., Quratulain, S., \& Bell, C.,M. (2014). Episodic envy and counterproductive work behaviors: Is more justice always good? Journal of Organizational Behavior, 35, 128-144. doi:10.1002/job.1864

Kirrane, M., O' Shea, D., Buckley, F., Grazi, A., \& Prout, J. (2017). Investigating the role of discrete emotions in silence versus speaking up. Journal of Occupational and Organizational Psychology, 90(3), 354-378. doi:10.1111/joop.12175

Koning, L. F., \& Van Kleef, G. A. (2015). How leaders' emotional displays shape followers' organizational citizenship behavior. Leadership Quarterly, 26(4), 489-501. doi:10.1016/j.leaqua.2015.03.001

Lazarus, R. S. (1991). Emotion and adaptation. New York, NY: Oxford University Press.

Lebel, R. D. (2017). Moving beyond fight and flight: A contingent model of how the emotional regulation of anger and fear sparks proactivity. Academy of Management Review, 42(2), 190-206. doi:10.5465/amr.2014.0368 
Lench, H. C., Flores, S. A., \& Bench, S. W. (2011). Discrete emotions predict changes in cognition, judgment, experience, behavior, and physiology: A meta-analysis of experimental emotion elicitations. Psychological Bulletin, 137(5), 834-855. doi:10.1037/a0024244

Lerner, J., Li, Y., Valdesolo, P., \& Kassam, K. S. (2015). Emotion and decision making. Annual Review of Psychology, 66, 799-823. doi:10.1146/annurev-psych-010213-115043

Lindebaum, D., \& Jordan, P. J. (2014). When it can be good to feel bad and bad to feel good: Exploring asymmetries in workplace emotional outcomes. Human Relations, 67(9), 1037-1050. doi:10.1177/0018726714535824

Hadley, C. N. (2014). Emotional roulette? Symmetrical and asymmetrical emotion regulation outcomes from coworker interactions about positive and negative work events. Human Relations, 67(9), 1073-1094. doi:10.1177/0018726714529316

Lindebaum, D., Jordan, P. J., \& Morris, L. (2016). Symmetrical and asymmetrical outcomes of leader anger expression: A qualitative study of army personnel. Human Relations, 69(2), 277-300. doi:10.1177/0018726715593350

Loukidou, L., Loan-Clarke, J., \& Daniels, K. (2009). Boredom in the workplace: More than monotonous tasks. International Journal of Management Reviews, 11(4), 381-405. doi:10.1111/j.1468-2370.2009.00267.x

Low, R. S. T., Overall, N. C., Hammond, M. D., \& Girme, Y. U. (2017). Emotional suppression during personal goal pursuit impedes goal strivings and achievement. Emotion, 17(2), 208223. doi:10.1037/emo0000218 
Lyubomirsky, S., King, L., \& Diener, E. (2005). The benefits of frequent positive affect:

Does happiness lead to success? Psychological Bulletin, 131, 803-855. doi:10.1037/00332909.131.6.803

Lyubomirsky, S., Sheldon, K. M., \& Schkade, D. (2005). Pursuing happiness: The architecture of sustainable change. Review of General Psychology, 9(2), 111-131. doi:10.1037/10892680.9.2.111

Maitlis, S., Vogus, T. J., \& Lawrence, T. B. (2013). Sensemaking and emotion in organizations. Organizational Psychology Review, 3(3), 222-247. doi:10.1177/2041386613489062

Martinovski, B. (2015). Emotion in group decision and negotiation. Dordrecht: Springer Netherlands.

Mehl, M. R., \& Conner, T. A. (2011). Handbook of research methods for studying daily life. New York, NY: Guilford Press.

Meier, L. L., Cho, E., \& Dumani, S. (2016). The effect of positive work reflection during leisure time on affective well-being: Results from three diary studies. Journal of Organizational Behavior, 37(2), 255-278. doi:10.1002/job.2039

Melwani, S., \& Barsade, S. G. (2011). Held in contempt: The psychological, interpersonal, and performance consequences of contempt in a work context. Journal of Personality and Social Psychology, 101(3), 503-520. doi:10.1037/a0023492

Melwani, S., Mueller, J. S., \& Overbeck, J. R. (2012). Looking down: The influence of contempt and compassion on emergent leadership categorizations. Journal of Applied Psychology, 97(6), 1171-1185. doi:10.1037/a0030074 
Menges, J., \& Kilduff, M. (2015). Group emotions: Cutting the Gordion knots concerning terms, levels-of-analysis, and processes. The Academy of Management Annals, 9, 845 928. doi: 10.1080/19416520.2015.1033148

Meyers, M. C., Van Woerkom, M., \& Bakker, A. B. (2013). The added value of the positive: A literature review of positive psychology interventions in organizations. European Journal of Work and Organizational Psychology, 22(5), 618-632.

doi:10.1080/1359432X.2012.694689

Miao, C., Humphrey, R. H., \& Qian, S. (2017). A meta-analysis of emotional intelligence and work attitudes. Journal of Occupational and Organizational Psychology, 90(2), 177-202. doi://dx.doi.org/10.1111/joop.12167

Muller, A., Heiden, B., Herbig, B., Poppe, F., \& Angerer, P. (2015). Improving well-being at work: A randomized controlled intervention based on selection, optimization, and compensation. Journal of Occupational Health Psychology, 21(2), 169-

181. doi:10.1037/a0039676

Neumeier, L., Brook, L., Ditchburn, G., \& Sckopke, P. (2017). Delivering your daily dose of well-being to the workplace: A randomized controlled trial of an online well-being programme for employees. European Journal of Work and Organizational Psychology, 26(4), 555-573. doi:10.1080/1359432X.2017.1320281

Nolen-Hoeksema, S., Wisco, B. E., \& Lyubomirsky, S. (2008). Rethinking rumination. Perspectives on Psychological Science, 3(5), 400-424. doi:10.1111/j.17456924.2008.00088.x 
Oh, J., \& Farh, C. (2017). An emotional process theory of how subordinates appraise, experience, and respond to abusive supervision over time. Academy of Management Review, 42(2), 207-232. doi:10.5465/amr.2014.0347

Ohly, S., \& Schmitt, A. (2015). What makes us enthusiastic, angry, feeling at rest or worried? Development and validation of an affective work events taxonomy using concept mapping methodology. Journal of Business and Psychology, 30, 15-35. doi:10.1007/s10869-0139328-3

Olatunji B. O., Naragon-Gainey K., Wolitzky-Taylor K. B. (2013). Specificity of rumination in anxiety and depression: A multimodal meta-analysis. Clinical Psychology: Science and Practice, 20, 225-357. doi:10.1111/cpsp.12037

Olekalns, M., \& Druckman, D. (2014). With feeling: How emotions shape negotiation. Negotiation Journal, 30(4), 455-478. doi:10.1111/nejo.12071

Ortony, A., \& Turner, T. J. (1990). What's basic about basic emotions? Psychological Review, 97(3), 315-331. doi:10.1037/0033-295X.97.3.315

Ouweneel, E., Le Blanc, P. M., Schaufeli, W. B., \& Van Wijhe, C. I. (2012). Good morning, good day: A diary study on positive emotions, hope, and work engagement. Human Relations, 65(9), 1129-1154. doi:10.1177/0018726711429382

Overbeck, J. R., Neale, M. A., \& Govan, C. L. (2010). I feel, therefore you act: Intrapersonal and interpersonal effects of emotion on negotiation as a function of social power. Organizational Behavior and Human Decision Processes, 112(2), 126-139. doi:10.1016/j.obhdp.2010.02.004

Parke, M. R., \& Seo, M. (2017). The role of affect climate in organizational effectiveness. Academy of Management Review, 42(2), 334-360. doi:10.5465/amr.2014.0424 
Parks, A. C., \& Layous, K. (2016). Positive psychological interventions. In J. C. Norcross, G. R. VandenBos, D. K. Freedheim \& R. Krishnamurthy (Eds.), APA handbook of clinical psychology: Applications and methods (Vol. 3, pp. 439-449). Washington, DC: American Psychological Association.

Parks, A. C., Schueller, S. M., \& Tasimi, A. (2013). Increasing happiness in the general population: Empirically supported self-help? In S. David, I. Boniwell, \& A. C. Ayers (Eds.), Oxford Handbook of Happiness (pp. 962-977). Oxford: Oxford University Press.

Pekrun, R., \& Frese, M. (1992). Emotions in work and achievement. In C. L. Cooper and I. T. Robertson (Eds.), International Review of Industrial and Organizational Psychology (Vol. 7, pp. 153-200). Chichester, UK: Wiley.

Quoidbach, J., Mikolajczak, M., \& Gross, J. J. (2015). Positive interventions: An emotion regulation perspective. Psychological Bulletin, 141(3), 655-693. doi:10.1037/a0038648

Renninger, K. A., \& Hidi, S. E. (2016). The power of interest for motivation and engagement. New York, NY: Routledge/Taylor \& Francis Group.

Rothman, N. B., \& Melwani, S. (2017). Feeling mixed, ambivalent, and in flux: The social functions of emotional complexity for leaders. Academy of Management Review, 42(2), 259-282. doi:10.5465/amr.2014.0355

Sansone, C., Weir, C., Harpster, L., \& Morgan, C. (1992). Once a boring task always a boring task? Interest as a self-regulatory mechanism. Journal of Personality and Social Psychology, 63(3), 379-390. doi:10.1037/0022-3514.63.3.379

Schall, M., Goetz, T., Martiny, S., \& Hall, N. (2017). It ain’t over 'til it’s over: The effect of task completion on the savoring of success. Motivation and Emotion, 41, 38-50. doi:10.1007/s11031-016-9591-5 
Scherer, K. R. (2005). What are emotions? And how can they be measured? Social Science Information, 44(4), 695-729. doi:10.1177/0539018405058216

Schindler, I., Paech, J., \& Löwenbrück, F. (2015). Linking admiration and adoration to selfexpansion: Different ways to enhance one's potential. Cognition and Emotion, 29(2), 292310. doi:10.1080/02699931.2014.903230

Schindler, I., Zink, V., Windrich, J., \& Menninghaus, W. (2012). Admiration and adoration: Their different ways of showing and shaping who we are. Cognition and Emotion 27, 85-118. doi:10.1080/02699931.2012.698253

Schlaerth, A., Ensari, N., \& Christian, J. (2013). A meta-analytical review of the relationship between emotional intelligence and leaders' constructive conflict management. Group Processes \& Intergroup Relations, 16, 126-136. doi://dx.doi.org/10.1177/1368430212439907

Seligman, M. E. P. (2011). Flourish: A visionary new understanding of happiness and wellbeing. New York, NY: Simon and Schuster.

Semmer, N. K., Messerli, L., \& Tschan, F. (2016). Disentangling the components of surface acting in emotion work: Experiencing emotions may be as important as regulating them. Journal of Applied Social Psychology, 46, 46-64. doi:10.1111/jasp.12364

Sharna, S. L., Desiree, K., \& Stephen, P. (2015). Resilience and the role of savouring pleasure. Frontiers in Psychology, 6, 00010. doi:10.3389/conf.fpsyg.2015.66.00010

Shariff, A. F., \& Tracy, J. L. (2009). Knowing who's boss: Implicit perceptions of status from the nonverbal expression of pride. Emotion, 9(5), 631-639. doi:10.1037/a0017089 
Shaver, P., Schwartz, J., Kirson, D., \& O'Connor, C. (1987). Emotion knowledge: Further exploration of a prototype approach. Journal of Personality and Social Psychology, 52(6), 1061-1086. doi:10.1037/0022-3514.52.6.1061

Sheldon, K. M., Boehm, J. K., \& Lyubomirsky, S. (2012). Variety is the spice of happiness: The hedonic adaptation prevention (HAP) model. In I. Boniwell \& S. David (Eds.), Oxford handbook of happiness (pp. 901-914). Oxford, England: Oxford University Press.

Sheldon, K., \& Lyubomirsky, M. (2006). Achieving sustainable gains in happiness: Change your actions, not your circumstances. Journal of Happiness Studies, 7, 55-86. doi:10.1007/s10902-005-0868-8

Silvia, P. J. (2006). Exploring the psychology of interest. Oxford: Oxford University Press.

Sin, N. L. \& Lyubomirsky, S. (2009). Enhancing well-being and alleviating depressive symptoms with positive psychology interventions: A practice-friendly meta-analysis. Journal of Clinical Psychology, 65(5), 467-487. doi:10.1002/jclp.20593

Sinaceur, M., Van Kleef, G. A., Neale, M. A., Adam, H., \& Haag, C. (2011). Hot or cold: Is communicating anger or threats more effective in negotiation? Journal of Applied Psychology, 96(5), 1018-1032. doi:10.1037/a0023896

Slovic, P., Finucane, M. L., Peters, E., \& Macgregor, D. G. (2007). The affect heuristic. European Journal of Operational Research, 177(3), 1333-1352. doi:10.1016/j.ejor.2005.04.006

Smith, J. M., \& Alloy, L. B. (2009). A roadmap to rumination: A review of the definition, assessment, and conceptualization of this multifaceted construct. Clinical Psychology Review, 29(2), 116-128. doi:10.1016/j.cpr.2008.10.003 
Smith, C. A., \& Ellsworth, P. C. (1985). Patterns of cognitive appraisal in emotion. Journal of Personality and Social Psychology, 48(4), 813-838. doi:10.1037/0022-3514.48.4.813

Speer, M., \& Delgado, M. (2017). Reminiscing about positive memories buffers acute stress responses. Nature Human Behavior, 1(5). doi:10.1038/s41562-017-0093

Spreitzer, G., Sutcliffe, K., Dutton, J., Sonenshein, S., \& Grant, A. M. (2005). A socially embedded model of thriving at work. Organization Science, 16(5), 537-549. doi:10.1287/orsc.1050.0153

Spence, J. R., Brown, D. J., Keeping, L. M., \& Lian, H. (2014). Helpful today, but not tomorrow? Feeling grateful as a predictor of daily organizational citizenship behaviors. Personnel Psychology, 67(3), 705-738. doi:10.1111/peps.12051

Stickney, L. T., \& Geddes, D. (2014). Positive, proactive, and committed: The surprising connection between good citizens and expressed (vs. suppressed) anger at work. Negotiation and Conflict Management Research, 7(4), 243-264. doi:10.1111/ncmr.12040

Tai, K., Narayanan, J., \& Mcallister, D. J. (2012). Envy as pain: Rethinking the nature of envy and its implications for employees and organizations. Academy of Management Review, 37, 107-129. doi:10.5465/amr.2009.0484

Tenney, E. R., Poole, J. M., \& Diener, E. (2016). Does positivity enhance work performance? Why, when, and what we don't know. Research in Organizational Behavior, 36, 27-46. doi://doi.org/10.1016/j.riob.2016.11.002

Thiel, C. E., Connelly, S., \& Griffith, J. A. (2012). Leadership and emotion management for complex tasks: Different emotions, different strategies. The Leadership Quarterly, 23(3), 517-533. doi:10.1016/j.leaqua.2011.12.005 
Thiel, C., Griffith, J., \& Connelly, S. (2015). Leader-follower interpersonal emotion management. Journal of Leadership \& Organizational Studies, 22, 5-20. doi:10.1177/1548051813515754

Thomas, D. L., \& Diener, E. (1990). Memory accuracy in the recall of emotions. Journal of Personality and Social Psychology, 59(2), 291-297. doi:10.1037/0022-3514.59.2.291

To, M. L., Fisher, C. D., Ashkanasy, N. M., \& Rowe, P. A. (2012). Within-person relationships between mood and creativity. Journal of Applied Psychology, 97(3), 599-612. doi:10.1037/a0026097

Tracy, J. L., \& Robins, R. W. (2007). The psychological structure of pride: A tale of two facets. Journal of Personality \& Social Psychology, 92(3), 506-525. doi:10.1037/00223514.92.3.506

Tse, H. H. M., Lam, C. K., Lawrence, S. A., \& Huang, X. (2013). When my supervisor dislikes you more than me: The effect of dissimilarity in leader member exchange on coworkers' interpersonal emotion and perceived help. Journal of Applied Psychology, 98(6), 974-988. doi:10.1037/a0033862

Van de Ven, N. (2017). Envy and admiration: Emotion and motivation following upward social comparison. Cognition and Emotion, 31, 193-200. doi:10.1080/02699931.2015.1087972

Van de Ven, N., Hoogland, C. E., Smith, R. H., Van Dijk, W. W., Breugelmans, S. M., \& Zeelenberg, M. (2015). When envy leads to schadenfreude. Cognition and Emotion, 29(6), 1007-1025. doi:10.1080/02699931.2014.961903

Van den Heuvel, M., Demerouti, E., \& Peeters, M. C. W. (2015). The job crafting intervention: Effects on job resources, self-efficacy, and affective well-being. Journal of Occupational and Organizational Psychology, 88(3), 511-532. doi:10.1111/joop.12128 
Van der Schalk, J., Kuppens, T., Bruder, M., \& Manstead, A. S. R. (2015). The social power of regret: The effect of social appraisal and anticipated emotions on fair and unfair allocations in resource dilemmas. Journal of Experimental Psychology: General, 144, 151-157. doi: 10.1037/xge0000036

Van Kleef, G. (2014). Understanding the positive and negative effects of emotional expressions in organizations: EASI does it. Human Relations, 67(9), 1145-1164. doi:10.1177/0018726713510329

Van Kleef, G. A. (2010). The emerging view of emotion as social information. Social and Personality Psychology Compass, 4(5), 331-343. doi:10.1111/j.1751-9004.2010.00262.x

Van Kleef, G. A., \& Côté, S. (2007). Expressing anger in conflict: When it helps and when it hurts. Journal of Applied Psychology, 92(6), 1557-1569. doi:10.1037/00219010.92.6.1557

Van Knippenberg, D., \& Van Kleef, G. A. (2016). Leadership and affect: Moving the hearts and minds of followers. Academy of Management Annals, 10, 799-840. doi:10.1080/19416520.2016.1160515

Van Tilburg, W. A., \& Igou, E. R. (2012). On boredom: Lack of challenge and meaning as distinct boredom experiences. Motivation and Emotion, 36, 181-194. doi://dx.doi.org/10.1007/s11031-011-9234-9

Veiga, J. F., Baldridge, D. C., \& Markoczy, L. (2014). Toward greater understanding of the pernicious effects of workplace envy. The International Journal of Human Resource Management, 25(17), 2364-2381. doi:10.1080/09585192.2013.877057 
Verbeke, W., Belschak, F., \& Bagozzi, R. (2004). The adaptive consequences of pride in personal selling. Journal of the Academy of Marketing Science, 32(4), 386-402. doi:10.1177/0092070304267105

Visser, V. A., Van Knippenberg, D., Van Kleef, G. A., \& Wisse, B. (2013). How leader displays of happiness and sadness influence follower performance: Emotional contagion and creative versus analytical performance. Leadership Quarterly, 24(1), 172188. doi.org/10.1016/j.leaqua.2012.09.003

Walter, F., Cole, M. S., \& Humphrey, R. H. (2011). Emotional intelligence: Sine qua non of leadership or folderol? Academy of Management Perspectives, 25, 45-59. doi:10.5465/AMP.2011.59198449

Wang, M., Liu, S., Liao, H., Gong, Y., Kammeyer-Mueller, J., \& Shi, J. (2013). Can’t get it out of my mind: Employee rumination after customer mistreatment and negative mood in the next morning. Journal of Applied Psychology, 98(6), 989-1004. doi:10.1037/a0033656

Wang, Y., \& Sung, W. (2016). Predictors of organizational citizenship behavior: Ethical leadership and workplace jealousy. Journal of Business Ethics, 135, 117-128. doi:10.1007/s10551-014-2480-5

Webb, T. L., Miles, E., \& Sheeran, P. (2012). Dealing with feeling: A meta-analysis of the effectiveness of strategies derived from the process model of emotion regulation. Psychological Bulletin, 138(4), 775-808. doi:10.1037/a0027600

Wegge, J., Dick, R. V., Fisher, G. K., West, M. A., \& Dawson, J. F. (2006). A test of basic assumptions of affective events theory (AET) in call centre work 1. British Journal of Management, 17(3), 237-254. doi:10.1111/j.1467-8551.2006.00489.x 
Weidman, A. C., Tracy, J. L., \& Elliot, A. J. (2016). The benefits of following your pride: Authentic pride promotes achievement. Journal of Personality, 84(5), 607-622. doi:10.1111/jopy.12184

Weiss, H. M. \& Beal, D. J. (2005). Reflections on affective events theory. Research on Emotion in Organizations, 1, 1-21. doi:10.1016/S1746-9791(05)01101-6

Weiss, H. M., \& Cropanzano, R. (1996). Affective events theory: A theoretical discussion of the structure, causes and consequences of affective experiences at work. Research in Organizational Behavior, 18, 1-74.

Williams, L. A., \& DeSteno, D. (2008). Pride and perseverance: The motivational role of pride. Journal of Personality \& Social Psychology. 94(6),1007-1017. doi:10.1037/00223514.94.6.1007

Winslow, C. J., Kaplan, S. A., Bradley-Geist, J., Lindsey, A. P., Ahmad, A. S., \& Hargrove, A. K. (2017). An examination of two positive organizational interventions: For whom do these interventions work? Journal of Occupational Health Psychology, 22, 129137. doi:10.1037/ocp0000035 